\title{
Análise da utilização de abrigos termo-higrométricos alternativos para transectos móveis
}

O método do transecto móvel é a realização de um percurso previamente determinado registrando as medições dos dados climáticos e é uma opção viável especialmente na investigação de ilhas de calor. Mirando prover subsídios, técnicas e procedimentos aos estudos de clima urbano com utilização de transectos móveis é proposto como objetivo geral analisar o desempenho termo-higrométrico de abrigos micrometeorológicos de diferentes tipos para coletas de dados. Para o desenvolvimento da pesquisa foram identificados na literatura os tipos de abrigos termo-higrômetros já estudados e quantificados para análise; escolhidos 5 tipos de abrigos que foram construídos, juntamente com datalogger, os sensores foram calibrados para então serem realizados transectos e após validados os dados foram analisados estatisticamente. Os resultados da análise estatística da parte experimental indicaram como significativas as interações: Temperatura e Turno; Temperatura e Período; Umidade e Turno; Umidade e Mês; Umidade e Estação; Umidade e Período. Já as interações não significativas foram: Temperatura e Mês; Temperatura e Estação; Temperatura e Ponto; Umidade e Ponto. O abrigo comercial adotado foi elencado como referência, pois é o possível de ser utilizado em trabalhos em qualquer parte do mundo. Para estudos de ilhas de calor realizadas no período noturno, todos os abrigos alternativos analisados foram eficientes. O modelo alternativo aqui denominado 'PVC horizontal' apresentou resultados totalmente favoráveis em todos os cenários e análises realizadas. $\mathrm{O}$ modelo impresso em impressora 3D foi eficaz em quase todas as situações. O modelo com 'pratos plásticos' e o de 'PVC vertical' não se mostraram eficientes.

Palavras-chave: Abrigos meteorológicos; Ilha de calor; Clima urbano.

\section{Analysis of the use of alternative thermo-hygrometric shelters for mobile transects}

\begin{abstract}
The mobile transect method is the completion of a predetermined path recording the measurements of climate data and is a viable option, especially in the investigation of heat islands. Aiming to provide subsidies, techniques and procedures to urban climate studies using mobile transects, it is proposed as a general objective to analyze the thermo-hygrometric performance of micrometeorological shelters of different types for data collection. For the development of the research were identified in the literature the types of shelters thermohygrometers already studied and quantified for analysis; 5 types of shelters were chosen together with datalogger, the sensors were calibrated so that transects were performed and after validation the data were analyzed statistically. The results of the statistical analysis of the experimental part indicated as significant the interactions: Temperature and Turn; Temperature and Period; Humidity and Shift; Humidity and Month; Humidity and Station; Humidity and Period. Non-significant interactions were: Temperature and Month; Temperature and Station; Temperature and Point; Humidity and Point. The commercial shelter adopted was listed as a reference, as it is possible to be used in works anywhere in the world. For studies of heat islands performed at night, all the alternative shelters analyzed were efficient. The alternative model here called 'horizontal PVC' presented totally favorable results in all the scenarios and analyzes carried out. The model printed on a 3D printer was effective in almost every situation. The model with 'plastic plates' and the 'vertical PVC' model were not efficient.
\end{abstract}

Keywords: Meteorological shelters; Heat island; Urban climate.

Topic: Engenharia de Qualidade e Metrologia

Reviewed anonymously in the process of blind peer.
Received: 07/08/2020

Approved: $\mathbf{2 1 / 1 1 / 2 0 2 0}$
Marcos de Oliveira Valin Júnior (iD)

Instituto Federal de Mato Grosso, Brasil http://lattes.cnpq.br/1988817143994600

http://orcid.org/0000-0003-2961-2011

marcos.valin@cba.ifmt.edu.br

Flávia Maria de Moura Santos (iD

Universidade Federal de Mato Grosso, Brasil

http://lattes.cnpq.br/4000857814123856

http://orcid.org/0000-0002-6009-6185

flavia_mms@hotmail.com

\section{Referencing this:}

VALIN JUNIOR, M. O.; SANTOS, F. M. M.. Análise da utilização de abrigos termo-higrométricos alternativos para transectos móveis Engineering Sciences, v.8, n.3, p.53-64, 2020. DOI: http://doi.org/10.6008/CBPC2318-3055.2020.003.0006 


\section{INTRODUÇÃO}

No estudo da climatologia é imprescindível a prática de trabalhos em campo visando a obtenção de dados, envolvendo mais do que somente observação e pesquisas bibliográficas, normalmente visam a obtenção de dados de temperatura do ar, umidade relativa do ar, precipitação, radiação, entre outros. Esses dados são geralmente obtidos através do uso de equipamentos e sensores específicos, sendo que muitos desses necessitam de abrigos meteorológicos para proteção dos sensores e também para garantir a qualidade e padronização dos dados.

Um desses procedimentos é o denominado método do transecto móvel, que essencialmente versa em realizar as medições móveis em percursos a pé, em bicicleta ou veículos automotores e é muito empregado no estudo da climatologia urbana para verificar diferenças entre os parâmetros climáticos em pontos de distintas ocupações do solo, tendo-se difundido em função de sua aplicação relativamente mais simples e de baixo custo operacional do que a instalação de várias estações fixas para coleta dos dados.

A padronização dos instrumentos de coleta e abrigos utilizados é fundamental para a qualidade das pesquisas microclimáticas, visto que esses dados geralmente são a base desses estudos. É importante ainda que esses instrumentos sejam de fácil acesso e baixo custo.

As pesquisas sobre os sistemas urbanos são desenvolvidas majoritariamente por universidades e centros de ensino onde os recursos são limitados e dependentes de editais ou mesmo de recursos dos próprios pesquisadores.

Para contornar essas dificuldades, muitos sensores, abrigos e sistemas alternativos aos padrões são desenvolvidos, baseados na experiência e criatividade dos pesquisadores, o que implica em uma falta de padronização para estas pesquisas, dificultando a repetitividade e comparações dos estudos por outros pesquisadores.

Considerando a complexidade dos sistemas urbanos e a elevada importância dos estudos e monitoramentos das variáveis climáticas ao longo dos anos e do desenvolvimento das cidades, subsidiando, por exemplo, estudos de ilhas de calor, projetos de edificações, conforto ambiental, planejamento urbano e até para controle epidemiológico, é essencial que procedimentos e maneiras de coleta de dados sejam definidos, possibilitando comparações e análises sem interferências ocasionadas por fatores que margeiam.

Um desses fatores essenciais e com influência direta são os abrigos utilizados nos sensores, que tem a função de permitir uma boa ventilação natural por todos os lados, bloquear a entrada de chuva e de radiação solar direta. Porém, pensando nisso, diferentes autores desenvolveram abrigos alternativos para realização de pesquisas, contudo, observam-se diferenças em seus formatos, materiais e posições de instalação.

Distinguir os tipos de abrigos possíveis e avaliá-los quanto à utilização em situações diversas é de grande importância para validação e precisão de estudos microclimáticos. Barbosa et al. (2008) estudaram a utilização de abrigos para medições internas em edificações e Valin Junior et al. (2016) estudaram a utilização de abrigos para medições externas em pontos fixos. 
Almejando prover subsídios, técnicas e metodologias aos estudos de clima urbano e a padronização da instrumentação dos procedimentos de aferição do sistema de aquisição de dados para garantia de qualidade das pesquisas é proposto como objetivo geral analisar o desempenho termo higrométrico de abrigos micrometeorológicos de diferentes tipos e formas para coletas de dados em transectos móveis.

\section{MATERIAIS E MÉTODOS}

Os abrigos para a análise de desempenho escolhidos para a pesquisa, foram os tipos já utilizados no Programa de Pós-Graduação em Física Ambiental - PGFA da Universidade Federal de Mato Grosso - UFMT, na cidade de Cuiabá - MT, sendo os seguintes tipos:

1) Abrigo com tubo de PVC vertical - 'PVC vertical' (sensor 1; T1, UR1) (Figura 1 - item a);

O abrigo foi produzido com tubos de PVC rígidos, na cor branca, sendo necessário $0,6 \mathrm{~m}$ de comprimento no diâmetro de $100 \mathrm{~mm}$ e $0,5 \mathrm{~m}$ de comprimento no diâmetro de $75 \mathrm{~mm}$. $O$ tubo menor foi revestido na sua face externa por papel aluminizado com o auxílio cola branca, para proteger de possíveis efeitos de radiação térmica. (VALIN JUNIOR et al., 2016)

2) Abrigo produzido em impressora 3D - '3D' (Sensor 2, T2, UR2) (Figura 1 - item d);

A base para o desenvolvimento do abrigo foram as normas da Organização Meteorológica Mundial WMO (World Meteorological Organization) que especifica as condições necessárias para que uma média seja considerada válida. O projeto foi feito utilizando um software CAD para projetos mecânicos em 3D, e os protótipos foram fabricados em prototipadora 3D. O material testado foi o PLA (poli ácido láctico) que é biodegradável. (MARQUES, 2016)

3) Abrigo com pratos plásticos brancos - 'pratos' (Sensor 3, T3, UR3) (Figura 1 - item c);

Foi construído utilizando seis pratos redondos de plástico na cor branca. Nos pratos intermediários foram realizadas aberturas, para o posterior posicionamento do sensor. A distância entre os pratos foi de $2,5 \mathrm{~cm}$, assegurados através de mangueira de nível transparente cortados, sustentados por duas barras galvanizadas roscadas de $0,4 \mathrm{~cm}$ diâmetro, de modo a fixar os pratos sobrepostos. (...) O plástico utilizado neste tipo de recipiente, é do tipo poliestireno (PS), que tem como principais características ser impermeável, inquebrável, rígido, leve e brilhante. As dimensões dos pratos são as seguintes: fundo do prato (aba menor): 0,12m; aba maior do prato: 0,215m; e profundidade do prato: 0,03m. (VALIN JUNIOR et al., 2016)

4) Abrigo de referência comercial - 'comercial' (Sensor 4, T4, UR4), sendo o modelo S2160, com 16 placas, da marca Squitter (Figura 1 - item b);

Todas as partes de alumínio do abrigo são anodizadas respeitando-se normas para aplicações marítimas e recebem pintura a pó branca brilhante para diminuir a condutividade térmica. Os espaçadores de nylon também têm a função de isolar as peças de alumínio dos três eixos de montagem de aço inox, evitando-se corrosão por efeito de pilha. (SQUITTER, 2018)

5) Abrigo com tubo de PVC horizontal - 'PVC horizontal' (Sensor 5, T5, UR5) (Figura 1 - item e).

Para sua produção utilizou-se um tubo de PVC rígido, cor branca, de $75 \mathrm{~mm}$ de diâmetro e $0,25 \mathrm{~m}$ de comprimento. $\mathrm{O}$ tubo foi perfurado, com o auxílio de uma furadeira com broca de $4 \mathrm{~mm}$, para permitir a passagem de ar. Na parte superior do tubo foi colocado um CAP (tampa para tubo de esgoto) para proteger o sensor da radiação solar direta e precipitações. Um suporte também foi confeccionado com peças de PVC. (VALIN JUNIOR et al., 2016)

Para realização do presente trabalho foram coletados dados das variáveis termo-higrométricas. 


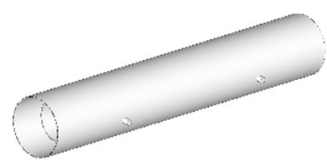

(a)

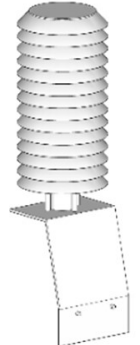

(b)

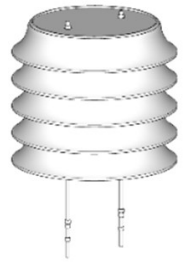

(c)

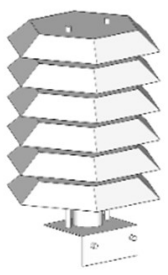

(d)

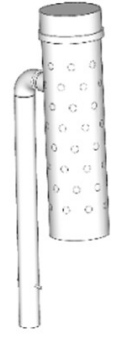

(e)

Figura 1: Abrigos utilizados: horizontal (a), comercial (b), pratos plásticos (c), impressora 3D (d) e vertical (e).

\section{Área de estudo}

Os sensores utilizados foram o do modelo DHT22 para medir a temperatura nas escalas de -40 a $125^{\circ} \mathrm{C}$ e a umidade do ar nas faixas de 0 a 100\%. O datalogger (Registrador de dados) foi programado em placa microcontroladora Raspberry Pi 3, cujas especificações estão apresentadas na Tabela 1. Os programas foram escritos na linguagem Python.

Tabela 1: Especificações.

\begin{tabular}{|l|l|}
\hline Sensor DHT22 & Processador Raspberry Pi 3 Modelo B \\
\hline - Tensão de alimentação: 3 - 5,5VDC; & - Tensão de operação: Micro USB 5V/2A; \\
- Faixa de Corrente: 0,5 2,5mA; & - SoC: Broadcom BCM2837 64bits; \\
- Faixa de operação de umidade: $0 \sim 100 \% ;$ & - Arquitetura: Quad-core ARMv8 Cortex-A53; \\
- Precisão de Umidade: $2 \%$ RH; & - Velocidade: $1.2 \mathrm{GHz} ;$ \\
- Faixa de operação da temperatura: -40 a $125^{\circ}$ Celsius; & - Memória: $1 \mathrm{~Gb}$ \\
- Precisão de Temperatura: 0, 20C; & - GPU: Broadcom VideoCore IV 3M (400 MHz); \\
- Dimensões totais (CxLxA): 36,5x15,2x9,4mm; & - Bluetooth 4.1 BLE: integrado; \\
& - Dimensões (CxLxA): 85x56x17mm; \\
\hline
\end{tabular}

Na proposta desta pesquisa com transecto é imprescindível a utilização do Módulo GPS + Antena, para o registro de cada coordenada relacionada com a temperatura e umidade registrada.

Os sensores foram calibrados para conferência das medidas, sendo todo o processo de calibração dos sensores encontra-se detalhado em Valin Junior et al. (2019).

\section{Instalação dos abrigos}

Os abrigos confeccionados foram fixados em uma régua metálica e posicionados em cima do carro com o auxílio de suportes. A distância entre eixos dos abrigos é de $0,3 \mathrm{~m}$ conforme Figura 2 - item a. Os abrigos fixos na régua possibilitam a fácil colocação e remoção para a realização dos transectos (Figura 2 item b).

A velocidade do veículo durante o percurso foi constante na maior parte do tempo em $30 \mathrm{~km} / \mathrm{h}$, com variações em curvas, semáforos, faixas de pedestres, trânsito intenso ou outras situações, porém nunca ultrapassando o limite de $30 \mathrm{~km} / \mathrm{h}$. 


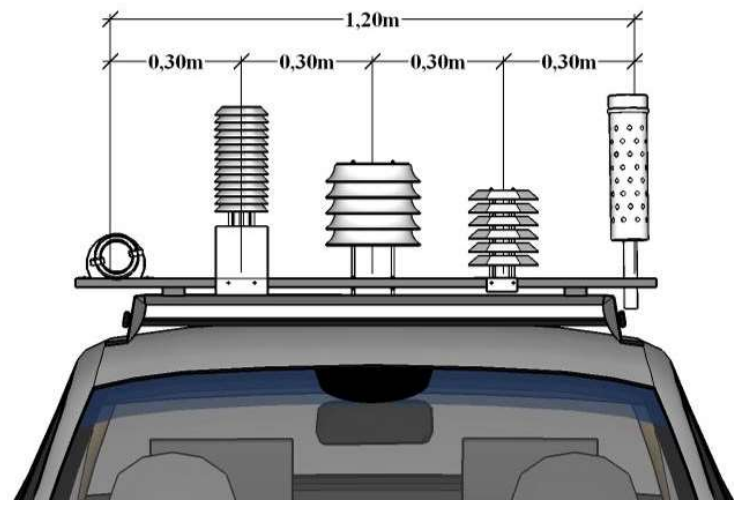

(a)

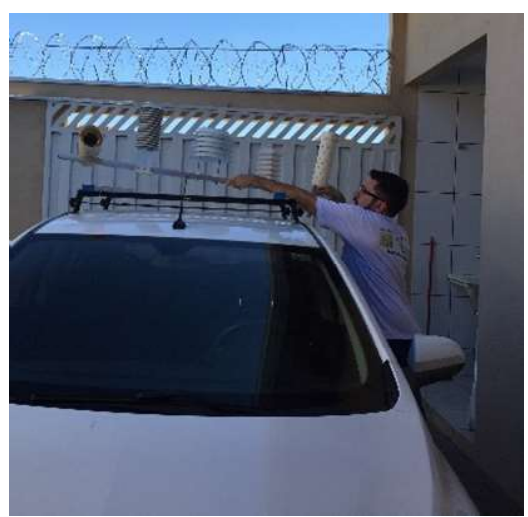

(b)

Figura 2: Posicionamento dos abrigos no veículo: (a) distâncias entre abrigos. (b) detalhe na instalação.

\section{Área de estudo do transecto}

O estudo foi desenvolvido no município de Cuiabá-MT, situado na região Centro-Oeste do Brasil a $15^{\circ} 35^{\prime} 46^{\prime \prime}$, latitude Sul e $56^{\circ} 05^{\prime} 48^{\prime \prime}$ de longitude Oeste, com altitude média inferior a $200 \mathrm{~m}$ acima do nível do mar. Possui uma área de $3.538,17 \mathrm{~km}^{2}$, correspondendo $254,57 \mathrm{~km}^{2}$ à macrozona urbana e $3.283,60 \mathrm{~km}^{2}$ à área rural.

O perfil climático é o tropical continental semiúmido do tipo Aw, segundo a classificação de KöppenGeiger, com quatro a cinco meses secos (maio a setembro) e máximas diárias de temperatura que oscilam entre $30^{\circ} \mathrm{C}$ e $36^{\circ} \mathrm{C}$, apresentando duas estações bem definidas, uma seca (outono-inverno) e uma chuvosa (primavera-verão) (SANTOS, 2012).

\section{Realização das medições/transectos}

O estudo foi desenvolvido no município de Cuiabá-MT, situado na região Centro-Oeste do Brasil a $15^{\circ} 35^{\prime} 46^{\prime \prime}$, latitude Sul e $56^{\circ} 05^{\prime} 48^{\prime \prime}$ de longitude Oeste, com altitude média inferior a $200 \mathrm{~m}$ acima do nível do mar. Possui uma área de $3.538,17 \mathrm{~km}^{2}$, correspondendo $254,57 \mathrm{~km}^{2}$ à macrozona urbana e $3.283,60 \mathrm{~km}^{2}$ à área rural.

O perfil climático é o tropical continental semiúmido do tipo Aw, segundo a classificação de KöppenGeiger, com quatro a cinco meses secos (maio a setembro) e máximas diárias de temperatura que oscilam entre $30^{\circ} \mathrm{C}$ e $36^{\circ} \mathrm{C}$, apresentando duas estações bem definidas, uma seca (outono-inverno) e uma chuvosa (primavera-verão) (SANTOS, 2012).

\section{Validações}

Como referência de comparação dos dados do transecto, optou-se por uma estação automatizada, modelo Vantage Pro $2^{\text {TM }}$ da marca Davis, (mod. 6382, Davis Instruments, USA) operando em intervalos de medição, conforme Tabela 2.

Tabela 2: Dados de precisão dos sensores da estação automatizada.

\begin{tabular}{|l|l|}
\hline Sensor: & Vantage Pro $2^{\mathrm{TM}}$ \\
\hline Faixa de medição: & Temperatura do ar: $-40^{\circ}$ a $65^{\circ} \mathrm{C} /$ Umidade relativa do ar: $1 \%$ a $100 \%$ \\
\hline Acurácia: & Temperatura do ar: $\pm 0,4^{\circ} \mathrm{C} /$ Umidade relativa do ar: $\pm 3 \%$ \\
\hline Resolução: & Temperatura do ar: $0,1^{\circ} \mathrm{C} /$ Umidade relativa do ar: $0,5 \%$ \\
\hline
\end{tabular}


A estação automatizada de referência foi instalada próximo ao Ponto 7 do transecto (Figura 3), no Programa de Pós-Graduação em Física Ambiental - PGFA, da Universidade Federal de Mato Grosso - UFMT.

Para validação da estação de referência foram utilizados os dados da Estação Meteorológica “CuiabáA901" do INMET (2018).

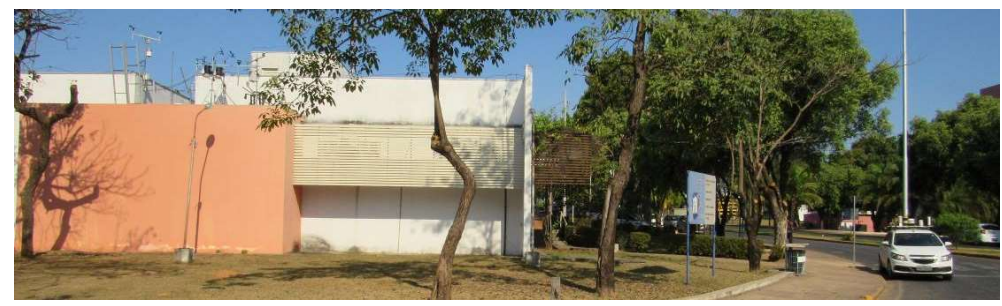

Figura 3: Estação automatizada instalada no Ponto 7 do transecto.

Para tal comparação utilizou-se o teste de qui-quadrado de aderência, que compara se os números de ambas as estações de fato diferem estatisticamente, ou se são mensurações similares. A comparação mostrou que as mensurações concordam entre si para a temperatura e a umidade relativa do ar, ou seja, as estações não diferem estatisticamente quanto as mensurações, conforme Tabela 3.

Tabela 3: Teste de qui-quadrado de aderência da estação de referência com o INMET.

\begin{tabular}{|l|l|l|l|}
\hline & Chi-Square & df & $\mathrm{p}$ \\
\hline Temperatura & 80,92 & 699 & 1,00 \\
\hline Umidade & 181,39 & 699 & 1,00 \\
\hline
\end{tabular}

A afirmação de que as estações não diferem estatisticamente quanto as mensurações é feita de acordo com o $p$ estatístico, sendo que o qui-quadrado é técnica que gerou o $p$ estatístico. A função deste teste é mostrar qual a probabilidade de um dado efeito que se manifesta na forma de correlação entre variáveis ou das diferenças serem fruto do acaso.

Para validação dos sensores do Transecto, foi utilizado apenas dos dados do Ponto 7, com os registros da Estação de Referência PGFA/UFMT, e também se utilizou o teste de qui-quadrado de aderência. A comparação mostrou que as mensurações concordam entre si para a temperatura e a umidade relativa do ar em todos os sensores, conforme Tabela 4.

Tabela 4: Teste de qui-quadrado de aderência dos sensores com a estação de referência.

\begin{tabular}{|l|l|l|l|l|}
\hline Sensor & Chi-Square Temp. & Chi-Square U.R. & df & $p$ \\
\hline Sensor 1 & 11,31 & 49,42 & 316 & 1,00 \\
\hline Sensor 2 & 8,23 & 57,27 & 316 & 1,00 \\
\hline Sensor 3 & 10,21 & 193,33 & 316 & 1,00 \\
\hline Sensor 4 & 15,74 & 63,89 & 316 & 1,00 \\
\hline Sensor 5 & 21,63 & 59,80 & 316 & 1,00 \\
\hline
\end{tabular}

Vale destacar que nesta fase de validação quando se afirma que os sensores não diferem estatisticamente quanto as mensurações da estação, o que está admitindo é que os dados são homogêneos, ou seja, que se comportam da mesma maneira.

\section{Análise dos dados do transecto}

Para as análises dos dados obtidos nos sensores procedeu-se com a técnica de Anova Fatorial através 
de um procedimento de modelo linear geral testando sempre 2 fatores por vez.

Todas as análises foram realizadas considerando os sensores já calibrados. Os testes foram realizados utilizando-se o software SPSS Statistics versão 22.0.

\section{RESULTADOS E DISCUSSÃO}

Foram realizados testes de efeito entre as variáveis (Temperatura do Ar e Umidade Relativa do Ar) obtidas nos 5 sensores/abrigos em relação ao Turno, Mês, Estação, Período e Ponto, sendo apresentados na Tabela 5.

Tabela 5: Testes de Efeito.

\begin{tabular}{|c|c|c|c|c|c|c|}
\hline Variável & & $\begin{array}{c}\text { Turno } \\
\text { (Mat., Vesp. e } \\
\text { Not.) }\end{array}$ & $\begin{array}{c}\text { Mês (Nov./2017 a } \\
\text { Out./2018) }\end{array}$ & $\begin{array}{c}\text { Estação } \\
\text { (Inv., Out., Prim. } \\
\text { e Ver.) }\end{array}$ & $\begin{array}{l}\text { Período (Seco e } \\
\text { Úmido) }\end{array}$ & $\begin{array}{c}\text { Ponto } \\
\text { (Fixos e } \\
\text { Trajetos) }\end{array}$ \\
\hline \multirow{3}{*}{$\begin{array}{l}\text { Temperatura do } \\
\mathrm{Ar}\end{array}$} & 'Sig' & $<0,0001$ & 0,870 & 0,342 & 0,034 & 1,00 \\
\hline & $\mathrm{F}$ & 143,36 & 0,76 & 1,11 & 2,60 & 0,45 \\
\hline & Interação & SIM & NÃO & NÃO & SIM & NÃO \\
\hline \multirow{3}{*}{$\begin{array}{l}\text { Umidade relativa } \\
\text { do } \mathrm{Ar}\end{array}$} & 'Sig' & $<0,0001$ & $<0,0001$ & $<0,0001$ & $<0,0001$ & 1,00 \\
\hline & $\mathrm{F}$ & 65,12 & 6,37 & 8,89 & 12,95 & 0,26 \\
\hline & Interação & SIM & SIM & SIM & SIM & NÃO \\
\hline
\end{tabular}

O valor de 'Sig' que representa o 'P estatístico', e espera-se que seja menor que 1 para que seja considerado significativo, e é tanto mais significativo quanto menor for seu valor. São aceitos como estatisticamente significativos os níveis $p=0,05$ e $p=0,01$, ou seja, $5 \%$ e $1 \%$ respectivamente.

No caso foram considerados significativos as interações: Temperatura e Turno; Temperatura e Período; Umidade e Turno; Umidade e Mês; Umidade e Estação; Umidade e Período.

Já as interações não significativas são: Temperatura e Mês; Temperatura e Estação; Temperatura e Ponto; Umidade e Ponto.

\section{Análises para dados de temperatura do ar}

$\mathrm{Na}$ análise quanto ao turno (Matutino, Vespertino e Noturno) o teste indicou que há interação entre sensor de temperatura do ar e turno. Isto é, ao pensar nas médias de temperatura entre os sensores, o turno deve ser considerado para uma interpretação adequada, o resultado se traduz no gráfico da Figura 4.

Já na análise mês a mês dos dados (Nov./2017 a Out./2018) o teste indicou que não há interação entre sensor e o mês, pois o valor de 'Sig' foi de 0,870. Ou seja, a diferença entre os sensores não é influenciada pelo mês, conforme gráfico da Figura 5.

A análise dos dados por estação do ano pelo teste indicou que não há interação entre sensor e a estação (Figura 6). Já na análise dos dados por período climático pelo teste de efeito entre as interações dos dados indicou que há interação entre sensor e o período (Figura 7). 


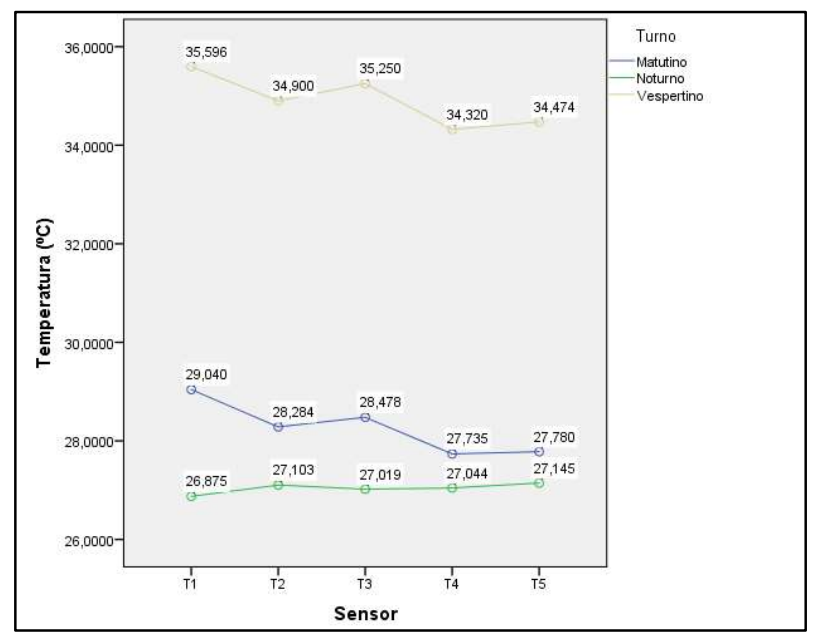

Figura 4: Temperatura média anual por turno.

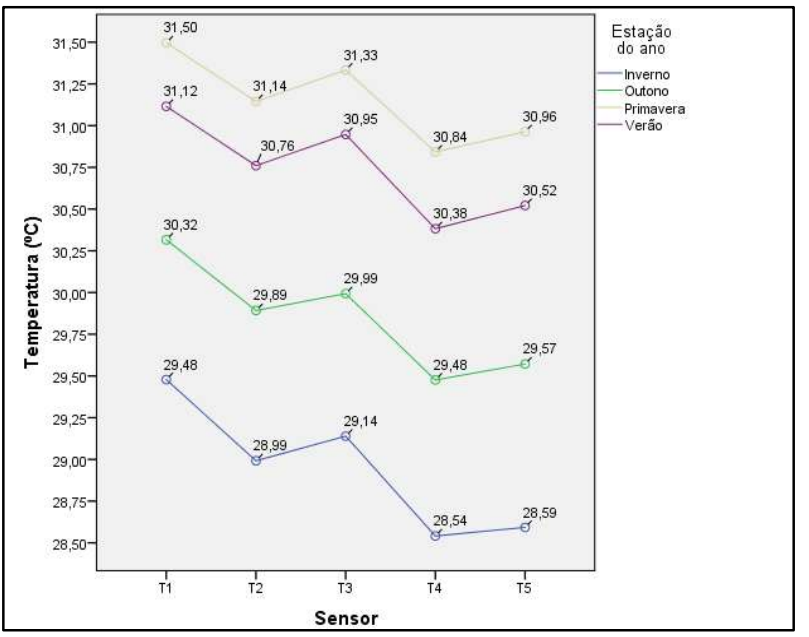

Figura 6: Temperatura média por estação.

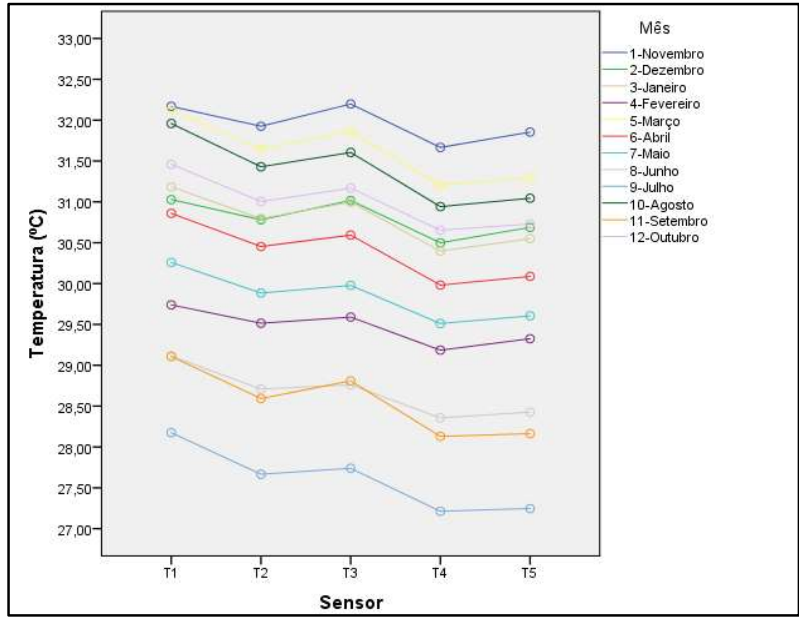

Figura 5: Temperatura média por mês.

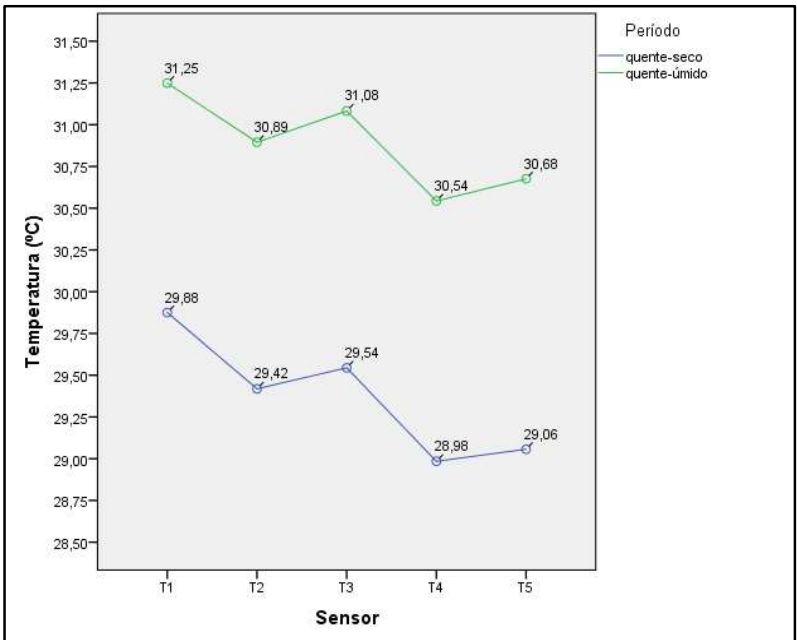

Figura 7: Temperatura média por período do ano.

Este fato ratifica o afirmado por Ribeiro et al. (2018) que a sazonalidade presente na região de Cuiabá é marcada por um período chuvoso e por um período seco.

Adotando o abrigo comercial (T4) como referência, tem-se na Tabela 6 a temperatura média obtida, subtraído do valor do abrigo comercial. Vale aqui destacar que a precisão do sensor é de 0,20 ㄴ , sendo assim constata-se que: para o período noturno todos os sensores mediram a mesma coisa, pois as variações são inferiores à precisão do sensor. No período matutino e vespertino o único dentro da precisão foi o abrigo horizontal; Entre os outros três abrigos fora da margem de erro do sensor, em todas as situações de análise, o erro mais próximo (menor) foi o abrigo produzido na impressora 3D, seguido pelo de pratos plásticos e o de PVC vertical.

Tabela 6: Diferença da temperatura entre abrigos.

\begin{tabular}{|l|l|l|l|l|l|l|}
\hline & & T1 - Vertical & T2 - 3D & T3 - Prato Plástico & T4 - Comercial & T5 - Horizontal \\
\hline \multirow{4}{*}{ Turno } & Matutino & 1,30 & 0,55 & 0,74 & 27,73 & 0,05 \\
\cline { 2 - 7 } & Vespertino & 1,27 & 0,58 & 0,93 & 34,32 & 0,15 \\
\cline { 2 - 7 } & Noturno & $-0,17$ & 0,06 & $-0,02$ & 27,04 & 0,10 \\
\hline \multirow{3}{*}{ Mês } & Média & 0,80 & 0,40 & 0,55 & 29,70 & 0,10 \\
& Nov/17 & 0,50 & 0,26 & 0,53 & 31,67 & 0,19 \\
\cline { 2 - 7 } & Dez/17 & 0,53 & 0,28 & 0,52 & 30,49 & 0,19 \\
\cline { 2 - 7 } & Jan/18 & 0,78 & 0,40 & 0,60 & 30,40 & 0,15 \\
\cline { 2 - 7 } & Fev/18 & 0,55 & 0,33 & 0,40 & 29,18 & 0,14 \\
\cline { 2 - 7 } & Mar/18 & 0,92 & 0,44 & 0,65 & 31,20 & 0,09 \\
\hline
\end{tabular}




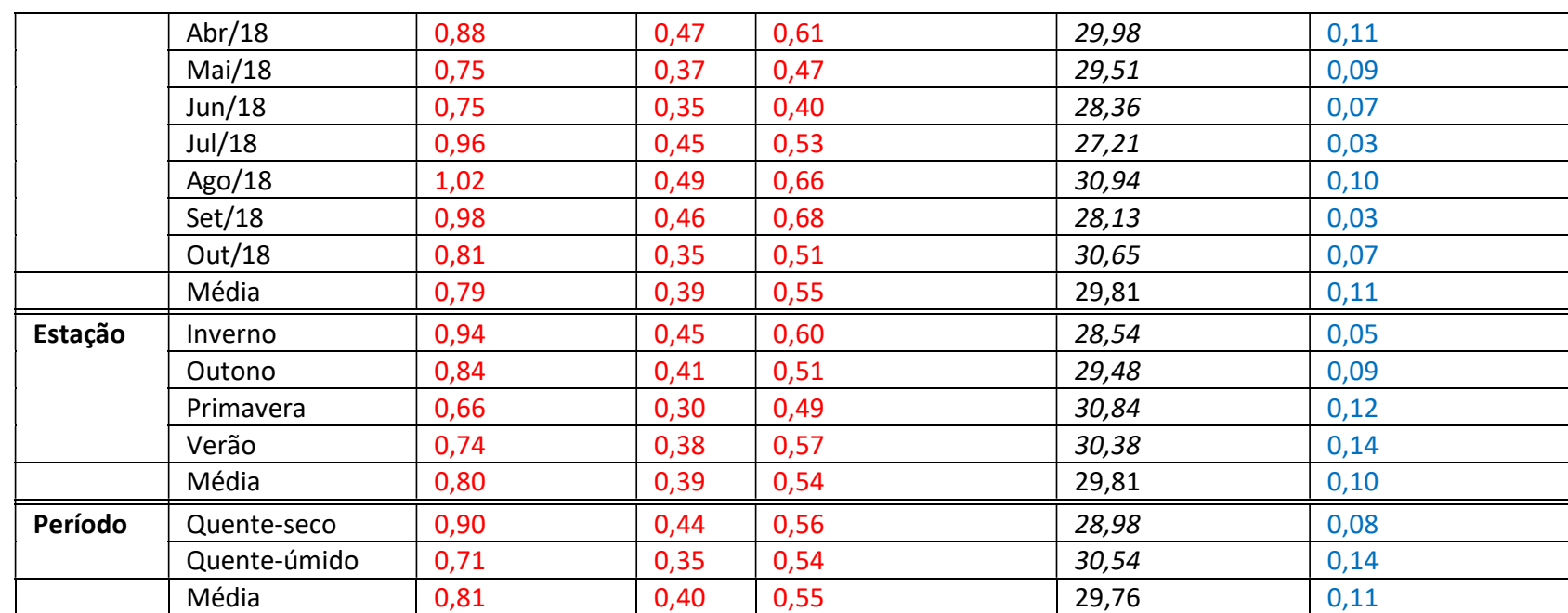

Interessante também destacar que os abrigos Vertical, 3D e de prato plástico apresentaram as maiores nos meses de agosto e setembro, que são ápices do período quente-seco.

\section{Análises para dados gerais de umidade relativa do ar}

A análise quanto ao turno o teste indicou que há interação com sensor de umidade relativa do ar, pois o valor de "Sig" foi menor que $0,1 \%$.

Portanto, ao pensar nas médias de umidade relativa do ar entre os sensores, o turno deve ser considerado para uma interpretação adequada, o resultado se traduz no gráfico da Figura 8, sendo que os sensores divergem entre si nos períodos matutino e vespertino, mas não no período noturno.

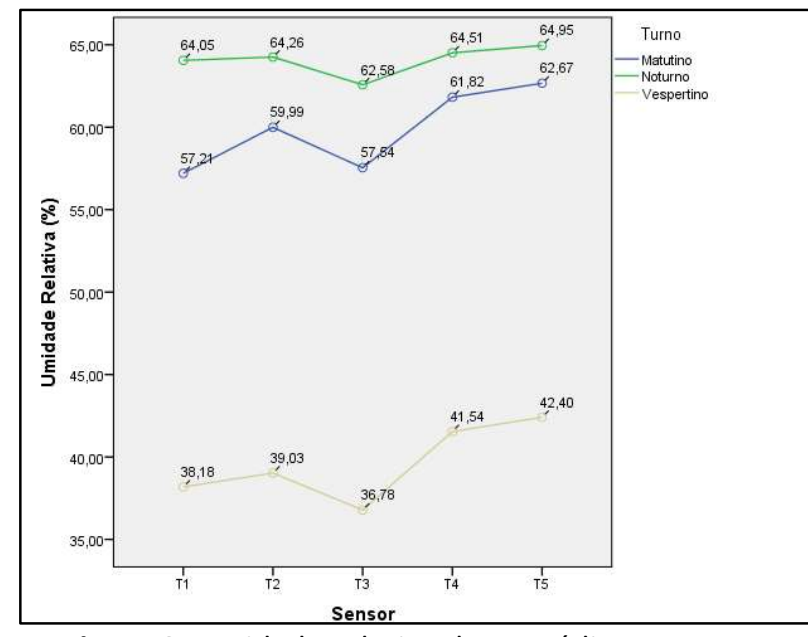

Figura 8: Umidade relativa do ar média por turno.

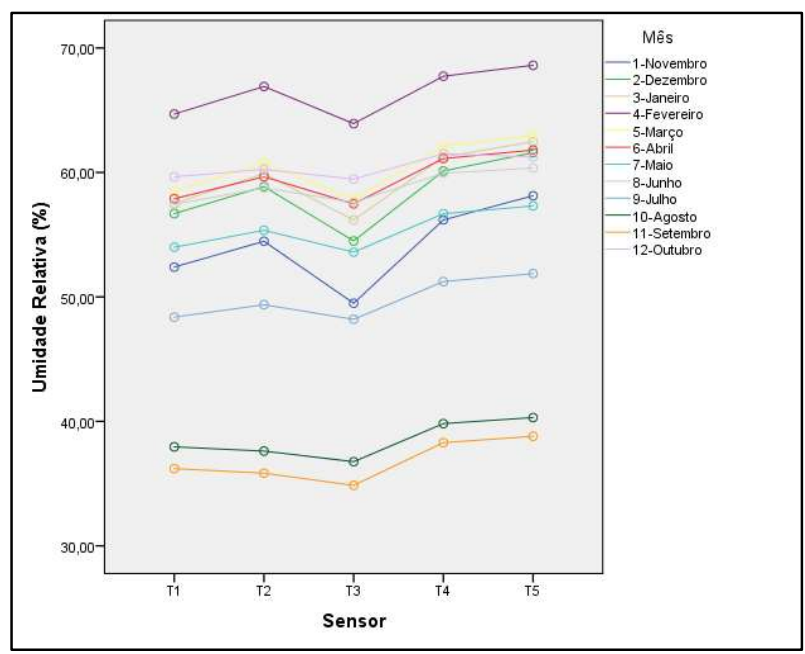

Figura 9: Umidade relativa do ar média por mês.

A análise mês a mês dos dados e por estação do pelos testes de efeito indicou que há interações respectivamente entre sensor e mês, e sensor e a estação, pois o valor de "Sig" foi menor que 0,1\% (altamente significativo) em ambos.

Existem diferenças entre os sensores de umidade influenciados pelo mês (diferentemente da temperatura), sendo que meses como novembro e fevereiro denotam diferenças bruscas, já meses como julho, diferenças muito sutis, conforme pode ser visto no gráfico da Figura 9.

Contata-se que há interação entre sensor e estação do ano (Figura 10), e por período climático (Figura 
11), pois em ambos o valor de "Sig" foi menor que 0,1\% (altamente significativo).

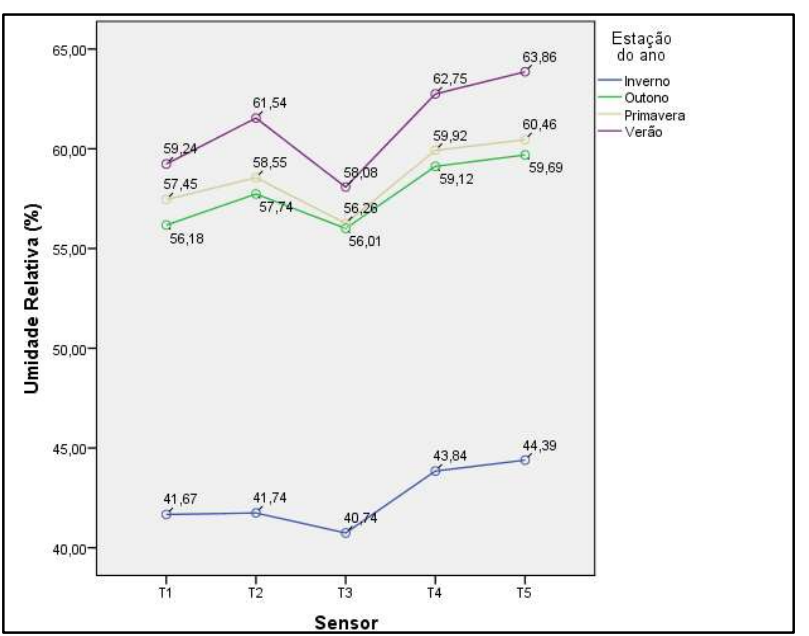

Figura 10: Umidade relativa do ar média por estação.

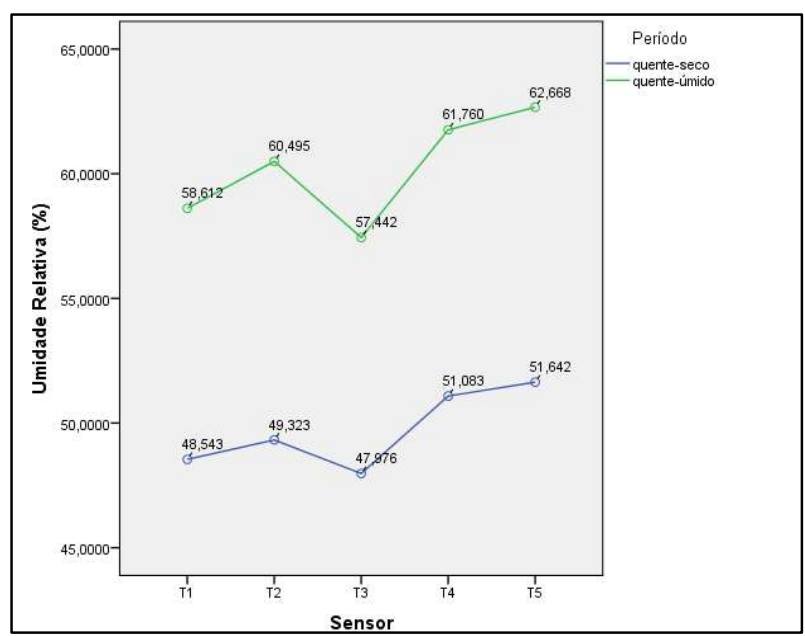

Figura 11: Umidade relativa do ar média por período do ano.

Adotando o abrigo comercial (T4) como referência tem-se na Tabela 7 os valores da temperatura média obtida nos abrigos subtraído do valor obtido no abrigo comercial. Insta mencionar que a precisão do sensor de umidade relativa é de $2 \%$, sendo assim constata-se como já observado nas interações detectadas nos testes estatísticos que a maioria das diferenças foram maiores do que o erro padrão do sensor no abrigo vertical e em todos com o prato plástico; sendo com poucas medições fora da margem com o abrigo 3D e totalmente dentro da margem o abrigo horizontal.

Tabela 7: Diferença da umidade entre abrigos.

\begin{tabular}{|c|c|c|c|c|c|c|}
\hline & & T1 - Vertical & T2 - 3D & T3 - Prato Plástico & T4-Comercial & T5 - Horizontal \\
\hline \multirow[t]{4}{*}{ Turno } & Matutino & $-4,61$ & $-1,83$ & $-4,28$ & 61,82 & 0,85 \\
\hline & Vespertino & $-3,36$ & $-2,51$ & $-4,76$ & 41,54 & 0,86 \\
\hline & Noturno & $-4,61$ & $-1,83$ & $-4,28$ & 61,82 & 0,85 \\
\hline & Média & $-4,19$ & $-2,05$ & $-4,44$ & 55,06 & 0,85 \\
\hline \multirow[t]{13}{*}{ Mês } & Nov/17 & $-3,79$ & $-1,71$ & $-6,7$ & 56,19 & 1,93 \\
\hline & Dez/17 & $-3,25$ & $-1,18$ & $-5,44$ & 59,94 & 1,55 \\
\hline & Jan/18 & $-3,74$ & $-1,35$ & $-5,07$ & 61,25 & 1,23 \\
\hline & Fev/18 & $-3,03$ & $-0,82$ & $-3,81$ & 67,73 & 0,87 \\
\hline & Mar/18 & $-3,60$ & $-1,32$ & $-4,20$ & 62,08 & 0,91 \\
\hline & Abr/18 & $-3,23$ & $-1,47$ & $-3,65$ & 61,12 & 0,68 \\
\hline & Mai/18 & $-2,69$ & $-1,34$ & $-3,09$ & 56,69 & 0,62 \\
\hline & Jun/18 & $-2,51$ & $-1,19$ & $-2,35$ & 59,95 & 0,40 \\
\hline & $\mathrm{Jul} / 18$ & $-2,85$ & $-1,85$ & $-3,03$ & 51,23 & 0,64 \\
\hline & Ago/18 & $-1,86$ & $-2,20$ & $-3,05$ & 39,82 & 0,48 \\
\hline & Set/18 & $-1,86$ & $-2,21$ & $-3,06$ & 39,82 & 0,49 \\
\hline & Out/18 & $-1,85$ & $-1,26$ & $-2,03$ & 61,50 & $-0,26$ \\
\hline & Média & $-2,85$ & $-1,49$ & $-3,79$ & 56,44 & 0,79 \\
\hline \multirow[t]{5}{*}{ Estação } & Inverno & $-2,17$ & $-2,10$ & $-3,10$ & 43,84 & 0,55 \\
\hline & Outono & $-2,94$ & $-1,38$ & $-3,11$ & 59,12 & 0,57 \\
\hline & Primavera & $-2,47$ & $-1,37$ & $-3,66$ & 59,92 & 0,54 \\
\hline & Verão & $-3,51$ & $-1,21$ & $-4,67$ & 62,75 & 1,11 \\
\hline & Média & $-2,77$ & $-1,51$ & $-3,63$ & 56,40 & 0,69 \\
\hline \multirow[t]{3}{*}{ Período } & Quente-seco & $-2,54$ & $-1,76$ & $-3,10$ & 51,08 & 0,56 \\
\hline & Quente-úmido & $-3,14$ & $-1,26$ & $-4,31$ & 61,76 & 0,90 \\
\hline & Média & $-2,84$ & $-1,51$ & $-3,71$ & 56,42 & 0,73 \\
\hline
\end{tabular}




\section{Análises pelos pontos do transecto}

Não há interação entre sensor de temperatura e pontos do transecto, e de forma similar, entre sensor de umidade e pontos do transecto, ou seja, a diferença entre os sensores não depende dos pontos $(P=1,0)$.

Há clara diferença entre os pontos, alguns registrando notoriamente maiores temperaturas (Figura 12 - item a) e umidade relativa (Figura 12 - item b) que outros.

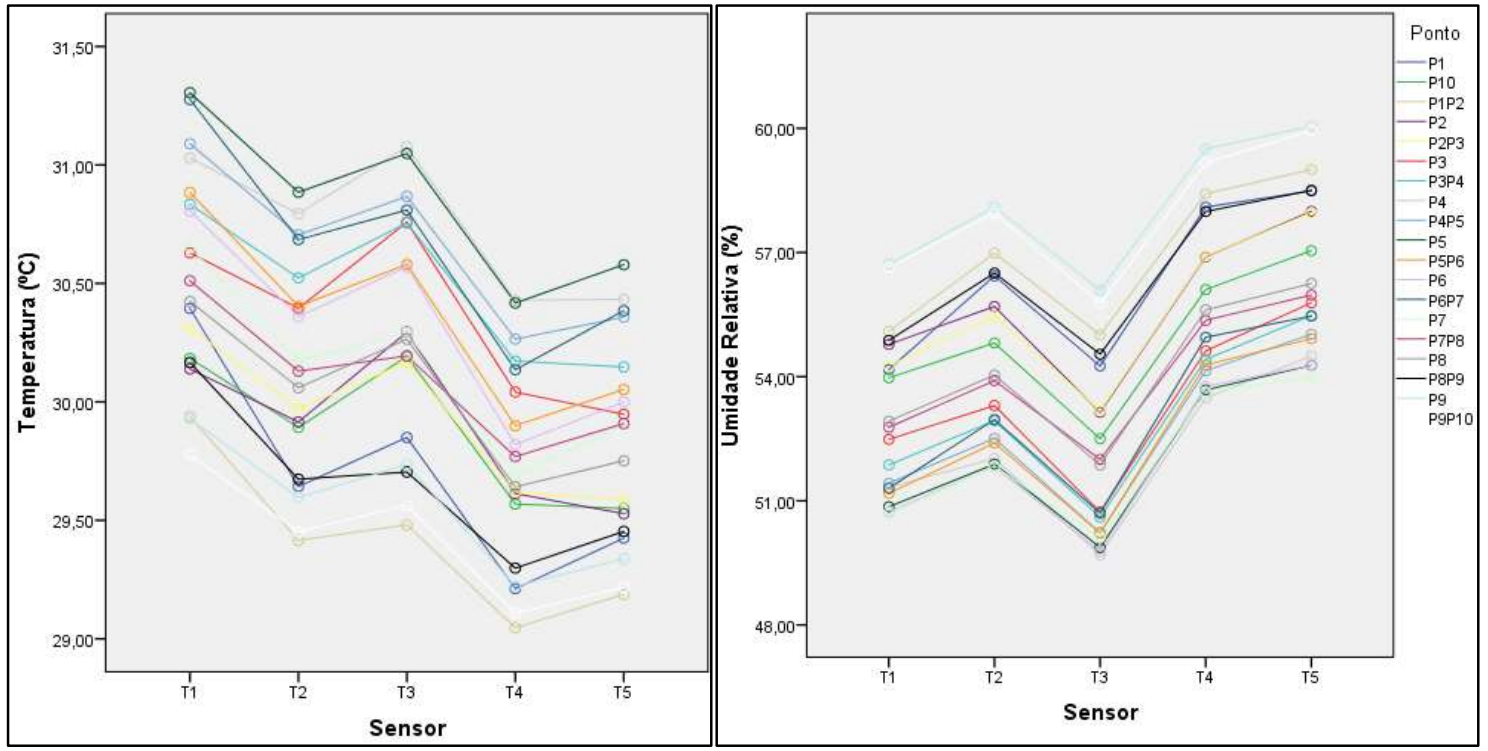

(a)

(b)

Figura 12: Temperatura do ar (a) e Umidade Relativa (b) média por ponto do transecto.

Pode parecer contraditório, mas são coisas distintas, a interação verifica se um dado sensor pode ter sido maior que outro apenas em algum ponto específico e o resultado mostra que não, ou seja, o mesmo padrão de diferenças entre os sensores se repete em todos os pontos (isso é o que é testado na interação), no entanto, claramente pontos como P5 tem temperaturas maiores que pontos como P1P2, por exemplo.

\section{CONCLUSÕES}

O abrigo comercial é a referência, pois é o possível de ser utilizado em trabalhos em qualquer parte do mundo. Para estudos de ilhas de calor realizadas no período noturno, todos os abrigos alternativos analisados foram eficientes.

O modelo alternativo aqui denominado "PVC horizontal" apresentou resultados totalmente favoráveis em todos os cenários e análises realizadas e, considerando os custos, vale ressaltar que é de apenas $3 \%$ do valor do abrigo comercial.

O modelo produzido em impressora 3D foi eficaz em quase todas as situações, enquanto que o modelo com "pratos plásticos" e o de "PVC vertical" não se mostraram eficientes. Este trabalho, tanto no estudo bibliográfico quanto no experimento realizado permitiu ratificar a importância na padronização dos equipamentos e procedimentos para a coleta de dados destes estudos do clima.

O transecto móvel é uma metodologia viável, flexível e de baixo custo, sendo que, com a adoção das 
recomendações de padronização realizadas neste estudo a qualidade dos trabalhos de identificação de variáveis climáticas como das ilhas de calor, ilhas de frescor, ilhas de umidade e ilhas secas poderão ser muito mais confiáveis e assim permitir a comparação dos dados entre diversas pesquisas em diferentes cidades do mundo com maior confiabilidade.

\section{REFERÊNCIAS}

BARBOSA, M. J.; LAMBERTS, R.; GUTHS, S.. Uso de barreiras de radiação para minimizar o erro no registro das temperaturas do ar em edificações. Ambiente Construído, Porto Alegre, v.8, n.4, p.117-136, 2008.

INMET. Instituto Nacional de Meteorologia. Dados da estação ‘Cuiabá-A901' código OMM ‘86705’. INMET, 2018.

MARQUES, J. B.. Desenvolvimento de sistema para monitoramento e aquisição de dados microclimáticos utilizando o programa EPICS. Tese (Doutorado em Física Ambiental) - Universidade Federal de Mato Grosso, Cuiabá, 2016.

RIBEIRO, K. F. A.; VALIN JUNIOR, M. O.; CHEGURY, J. Q. B. M.; SANTOS, F. M. M.; RODRIGUES, T. R.; CURADO, L. F. A.; NOGUEIRA, J. S.. Efeito do sombreamento arbóreo na temperatura superficial e no fluxo de energia em diferentes coberturas urbanas em Cuiabá/MT. Revista Sociedade e Natureza, v.30, n.1, p.183-204, 2018. Dol: http://doi.org/10.14393/SN-v30n1-2018-8
SANTOS, F. M. M.. Influência da ocupação do solo na variação termo-higrométrica na cidade de Cuiabá/MT. Tese (Doutorado em Física Ambiental) - Universidade Federal de Mato Grosso, Cuiabá, 2012.

SQUITTER. Meteorologia e Hidrologia. Abrigo meteorológico modelo sq15-s2160. SQUITTER, 2018.

VALIN JUNIOR, M. O.; SANTOS, F. M. M. ; RIBEIRO, K. F. A. ; NOGUEIRA, M. C. J. A.; NOGUEIRA, J. S.. Análise da relação entre abrigos meteorológicos alternativos para pontos fixos e o comportamento de variáveis termo-higrométricas. Revista Brasileira de Climatologia, v.18, p.157-179, 2016. DOI: http://dx.doi.org/10.5380/abclima.v18i0.45146

VALIN JUNIOR, M. O.; SANTOS, F. M. M.; MARQUES, J. B.; RIBEIRO, K. F. A.. Sensores Termo-higrométricos: Procedimentos para montagem e calibração. Revista Cientific@,v.6, p.134-143, 2019. DOI: http://doi.org/10.29247/2358-260X.2019v6i1.p134-143

A CBPC - Companhia Brasileira de Produção Científica (CNPJ: 11.221.422/0001-03) detém os direitos materiais desta publicação. Os direitos referem-se à publicação do trabalho em qualquer parte do mundo, incluindo os direitos às renovações, expansões e disseminações da contribuição, bem como outros direitos subsidiários. Todos os trabalhos publicados eletronicamente poderão posteriormente ser publicados em coletâneas impressas sob coordenação da Sustenere Publishing, da Companhia Brasileira de Produção Científica e seus parceiros autorizados. Os (as) autores (as) preservam os direitos autorais, mas não têm permissão para a publicação da contribuição em outro meio, impresso ou digital, em português ou em tradução. 